\title{
Date of otolith first increment formation in Baltic sprat Sprattus sprattus and its relation to onset of maturity
}

\author{
Patricia Reglero ${ }^{1,3, *}$, Henrik Mosegaard ${ }^{1}$, Hans Harald Hinrichsen ${ }^{2}$ \\ ${ }^{1}$ Danish Institute for Fisheries Research, Charlottenlund Slot, 2920 Charlottenlund, Denmark \\ ${ }^{2}$ Institut für Meereskunde, Düsternbrooker Weg 20, 24105 Kiel, Germany \\ ${ }^{3}$ Present address: Instituto Español de Oceanografía, Moll de Ponent S/N, 07015 Palma de Mallorca, Spain
}

\begin{abstract}
This study explores the date of first otolith increment formation in Baltic sprat Sprattus sprattus and relates the onset of maturity at Age 1 to the larval traits that are tied to the formation of the first increment. From the otolith microstructure analyses in larvae we found that regular deposition of increments is closely related to larval length, the first clear increment being identified at $16 \mathrm{~mm}$ length. Otolith distance from the centre to the first clear increment was independent of temperature, whereas the width of subsequent regular increments increased with increasing temperatures. These results are interpreted in the context of the interaction of larval length, somatic growth and environmental temperature. The date of first increment formation was further estimated in mature and immature Age 1 sprat caught from 1998 to 2000 using a technique that we developed, based on the effect of temperature on larval-stage otolith microstructure after first increment formation. The overall result was that larvae that reach the length of $16 \mathrm{~mm}$ early (late) in the season in warm years are more (less) likely to mature the following year. In cold years, like 1998, the probability of maturating at Age 1 was independent of the date at which larvae became $16 \mathrm{~mm}$ long, and other processes such as juvenile growth rates, feeding conditions and year-class abundance are suggested as factors that may influence the onset of maturity.
\end{abstract}

KEY WORDS: Baltic $\cdot$ Sprat $\cdot$ Otolith $\cdot$ First increment formation $\cdot$ Temperature $\cdot$ Maturity

\section{INTRODUCTION}

Some fish species, as e.g. clupeids, are able to attain maturity as early as Age 1 or 2 . In these cases, the performance of the individuals during their first year of life may have a significant influence on their onset of maturity. However, little is known about how phenotypic features early in life, such as hatch date and growth and survival, are related to the ability of a fish to attain first maturity at a given age and how differences in these features among members of the same population are established.

One important use of otoliths in the field of life-history studies is to estimate the timing of the first incre- ment formation, which is usually tied to a life-history event that may be hatching or some other trait, depending on the species (Campana \& Jones 1992). This otolith-based information can be used to link larval characteristics, particularly the larval traits that are tied to the formation of the first increment, to variability in further adult traits such as age at maturity. In larvae and juvenile fish, the date of formation of the first increment is calculated by counting the total number of increments towards the otolith edge. However, the same approach cannot readily be used in adults from temperate regions, because no distinguishable increments are recorded during the winter months (Campana \& Neilson 1985). 
Methods to determine the time of first increment formation in adults have been examined in detail for herring Clupea harengus. Otolith growth trajectories vary among larvae experiencing different temperature regimes (Moksness 1992, Fossum \& Moksness 1993, Stenevik et al. 1996, Fey 2001). Similar growth trajectories are further identified in otoliths of adults and have been successfully used to identify fish forming their first increment during the year (Zhang \& Moksness 1993, Mosegaard \& Madsen 1996). A similar approach may be used for other fish species given that temperature is one of the main factors controlling otolith increment formation (Marshall \& Parker 1982, Mosegaard et al. 1988).

Previous studies have shown the importance of considering hatch date to better understand further traits later in life (Wright \& Bailey 1996). For many species hatching extends over a significantly long period of the year, so that individuals hatched during the same spawning season may experience very different environmental conditions. Baltic sprat Sprattus sprattus has a prolonged spawning season that extends from April to August (Alheit 1988). During the spawning season there is a consistent increase in the temperature of the upper layers where larger sprat larvae usually concentrate (Wieland \& Zuzarte 1991, Makarchouk \& Hinrichsen 1998). Identification of the time of the year when larvae hatch is therefore important in order to establish further links between early development and adult characteristics. The growth and survival rates of larvae hatched during the same year can also differ depending on the specific hatch date. The influence of steadily increasing temperatures during the sprat spawning season is expected to affect somatic growth and otolith accretion rates that later may be recognised as specific microstructure patterns in the surviving adults. Differences in the characteristics such as somatic growth, already established at the larval stage, may further influence sprat adult traits and life-history strategies, the onset of maturity being one possible example.

This study explores the otolith microstructure of Baltic sprat and identifies when and which larval trait is tied to first increment formation. This larval trait is further identified in adults using a method to estimate date of first increment formation based on the temperature effect on the microstructure pattern of otoliths during the larval stage. Combining the otolith-based information with data on sprat maturity, we analysed if differences in the onset of maturity among sprat adults hatched during the same spawning season are already established in the first year of life during the larval stage - a result that would have important implications for the understanding of coexisting life-history traits with short or long generation time (Reglero \& Mosegaard 2006).

\section{MATERIALS AND METHODS}

Larvae and juveniles. Sprat Sprattus sprattus larvae were collected periodically in the Bornholm Basin, a principal spawning area in the Baltic Sea, during 1999. A standard oblique tow using a Bongo net with a diameter of $60 \mathrm{~cm}$ and $500 \mu \mathrm{m}$ mesh was conducted at every station at a speed of 3 knots. On 13 and 14 August, juveniles were collected using a fishing trawl at an average depth of 10 to $15 \mathrm{~m}$. At each station, sprat larvae and juveniles were identified, and a sub-sample was preserved in $96 \%$ alcohol for otolith analyses, except for those caught in the middle of August when individuals were frozen. A representative size range of larvae and juveniles from selected stations over time was analysed to cover all possible growth patterns formed in different temperature regimes (Table 1).

Adults. Adult sprat were sampled over the spawning season, from 1998 to 2000, from the Bornholm Basin. Samples were taken on research cruises conducted by the Danish Institute of Fisheries Research and the Institute of Marine Science in Kiel, as well as from the Danish small mesh commercial fishery.

All fish were measured (total length, TL), weighed and separated into juveniles, males, or females. The maturity stages of Baltic sprat were identified according to the 10 degree scale introduced by Aleksejev \& Aleksejeva (1996). A random sub-sample of Age 1 sprat from each year was selected for further otolith analysis (Table 1).

Table 1. Sprattus sprattus. Sample information, 1999-2000. Otoliths of Age 1 sprat were sampled from 1998 to 2000, from research cruises and/or the commercial fishery (CF). Number of fish is indicated (with number of Age 1 adults in parentheses). In development of methods, otoliths from larvae and juvenile sprat caught in 1999 on research cruises were further analysed for microstructure

\begin{tabular}{|c|c|c|c|c|c|}
\hline Stage & $\begin{array}{l}\text { Sampling } \\
\text { source }\end{array}$ & Year & Date & $\begin{array}{l}\text { n (no. of } \\
\text { Age } 1 \\
\text { adults) }\end{array}$ & $\begin{array}{c}\text { No. of } \\
\text { otoliths } \\
\text { analysed }\end{array}$ \\
\hline \multirow[t]{7}{*}{ Larva } & Cruise & 1999 & 19 May & 52 & 52 \\
\hline & & & 26 May & 106 & 106 \\
\hline & & & 4 Jun & 37 & 37 \\
\hline & & & Early Jul & 16 & 16 \\
\hline & & & $25 \mathrm{Jul}$ & 26 & 26 \\
\hline & & & $27 \mathrm{Jul}$ & 16 & 16 \\
\hline & & & 5 Aug & 13 & 13 \\
\hline $\begin{array}{l}\text { Larva, } \\
\text { juvenile }\end{array}$ & & & $14,15 \mathrm{Aug}$ & 85 & 85 \\
\hline Adult & $\begin{array}{l}\text { Industry, } \\
\text { CF }\end{array}$ & 1998 & Jan-Jul & 1205 & 76 \\
\hline Adult & $\begin{array}{l}\text { Industry, } \\
\quad \mathrm{CF}\end{array}$ & 1999 & Jan-May & 713 (23) & 23 \\
\hline Adult & Cruise & 2000 & Mar & $291(100)$ & 91 \\
\hline
\end{tabular}


Temperature regime. Combined vertical profiles of water temperature measured at different stations in the Bornholm Basin during 1997 to 1999 were used as initial conditions to a 3-dimensional eddy-resolving baroclinic model (henceforth referred to as the circulation model) based on the Bryan-Cox-Semtner code adapted for the Baltic Sea (Killworth et al. 1991, Lehmann 1995). All simulations were forced with actual wind data (provided by the Swedish Meteorological and Hydrological Institute, SMHI, Norrköping, Sweden) to generate the general Baltic circulation and mesoscale dynamics, resulting in simulated 3-dimensional temperature fields. The spatial resolution of the simulated data was $5 \mathrm{~km}$ horizontally and 41 levels vertically. The time step of the model was 5 min, but data were archived daily over the sprat spawning season, from 1997 to 1999. The temperature regimes in the upper $10 \mathrm{~m}$ during 1997 to 1999 were compared to those from 1968 to 1994 provided by the ICES Oceanographic Data Centre.

Otolith microstructure. The total length of each larva was measured under a dissection microscope connected to an image analysis system through a black and white camera with a resolution of 4.09 pixels $\mathrm{mm}^{-1}$. Total length estimates were not corrected for shrinkage in ethanol.

Both sagittal otoliths were identified for each larva using a magnification glass with double-polarised light, and removed using a pair of dissecting needles. In adults, both sagittal otoliths were dissected using forceps. All sagittal otoliths were mounted in thermoplastic cement (Buehler@) on individual standard glass microscope slides with the sulcus surface of the otolith facing downward.

Otoliths were polished on a polishing disc with 2 grades of sandpaper (30 and $3 \mu \mathrm{m}$ ) and subsequently using fine polishing paste with a particle size of $0.3 \mu \mathrm{m}$ (Alpha Micropolish Alumina ${ }^{\circledR}$ No. 2). The polishing procedure was such that all increments were visible in the same focal plane from the centre to the edge in larval otoliths, whereas in adult otoliths only the central part of the otolith surrounding the nucleus was enhanced.

Measurements of the distance from the centre to each increment and to the edge were performed in larval otoliths along the para-rostrum axis using an image analysis system (Image-Pro® Plus 4.1, Microsoft® Windows ${ }^{\mathrm{TM}}$ ). When no increments were identified, measurements from the centre to the edge were taken. In adults, only the distances from the centre to the first 7 increments were measured. The resolution was 2.61 and 9.82 pixels $\mu \mathrm{m}^{-1}$ for larval otoliths and 2.45 and 4.93 pixels $\mu \mathrm{m}^{-1}$ for juvenile and adult otoliths. The date of increment formation was estimated from the number of increments counted in the larval otoliths under the assumption that they were formed daily (Alshuth 1988, Ré \& Gonçalves 1993).

First increment formation. Simple linear regression analysis (PROC GLM; SAS v8.1) was used to relate otolith radius to first clear increment and temperature. Linear regression was also used to relate otolith distance-to-the-edge to fish length-at-catch.

Estimating time of first increment formation. The development of the method to estimate date of first increment formation followed 3 major steps (Fig. 1). First, the effect of temperature on the otolith growth pattern of larvae after first increment formation was analysed. Second, an expression was developed to estimate the temperature experienced by the larvae, which resulted in the observed otolith growth pattern. Third, the estimated temperatures experienced by the larvae were transformed to dates of first increment formation using the corresponding day of the yeartemperature relationship.

Step 1: Temperature influence on otolith growth: The effect of temperature on the otolith growth pattern during the larval stage after first increment deposition was analysed statistically by fitting a mixed linear model to the data using the method of restricted maximum likelihood (Proc Mixed, SAS v8.1). The dependent variable was the otolith increment width of larvae caught in 1999, whereas temperature at day of increment formation was considered as the independent variable. Because larger larvae concentrate in the upper layer of the water column at the time of first micro-increment formation (Reglero 2004), average daily temperatures in the upper $10 \mathrm{~m}$ were used in the analysis. Only the first 7 growth structures, corresponding to the maximum number of micro-increments found in the youngest larvae, were included in the analysis to avoid statistical treatment of missing

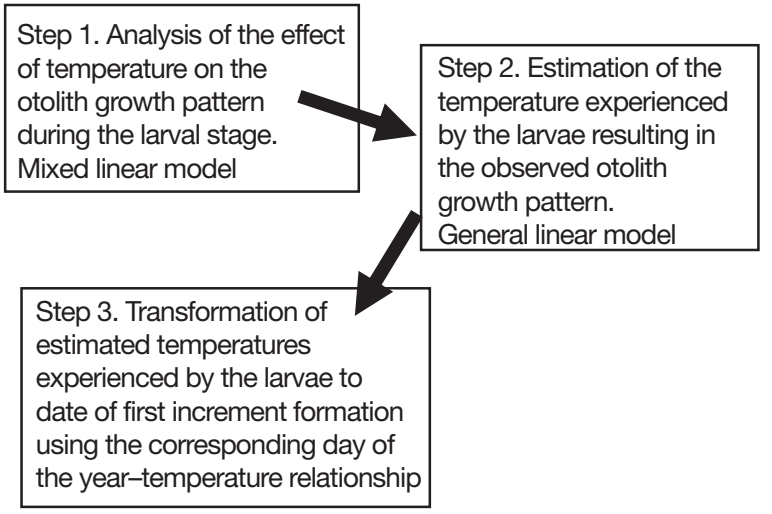

Fig. 1. Flow chart of steps involved in development of a method to estimate date of first clear increment formation using measurements of larval otoliths and temperature data from 1999 
values. All measurements were log-transformed to homogenise variances.

Step 2: Estimation of temperature at first microincrement formation: After showing significant effects of temperature on otolith growth during the larval stage, the relationship was turned around and the estimated temperature experienced by the larvae resulting in the observed otolith growth pattern was calculated using a general linear model (PROC GLM, SAS v8.1). Temperature was introduced as the dependent variable in the model, measured as the average temperature in the upper water layer in 1999 at the formation of the first 7 micro-increments. As independent variables, the first 7 increment widths of the larval otoliths and all possible interactions among them were considered a priori. Afterwards, the model was simplified by taking into account only the factors that had a significant effect $(\mathrm{p}<0.001)$ on the dependent variable.

Step 3: Estimation of date of first increment formation: Estimated temperatures from the general linear model (Step 2) were used as a proxy for date of first increment formation by searching for the day of the year when the difference between the temperatures from the circulation model and those estimated from the GLM exhibited a minimum. The accuracy of the method was evaluated by comparing the estimated temperature and dates at first micro-increment formation from the GLM, with the observed dates calculated from the otolith micro-increments readings. The suitability of the model, if errors in the location of the first increment occurred, was tested substituting the first 7 increment widths of the larval otoliths in Step 2 by the 7 increment widths found at a fixed distance of $30 \mu \mathrm{m}$ from the core.

The method was subsequently applied to estimate the temperatures at first increment formation of Age 1 sprat adults from 3 different year classes: 1997, 1998 and 1999. Dates of first increment formation were assigned to temperatures by finding the day that corresponded to the exact temperature value using the corresponding day of the year-temperature relationship provided by the circulation model. If the exact value was not found, the closest lowest value was assigned.

Effect of date of first increment formation on the proportion mature at Age 1. The effect of date of first increment formation on the proportion mature at Age 1 was analysed using GLM, where the dependent variable was the ratio between the number of mature individuals and the total number of individuals $(p)$ and the independent variable was the temperature at hatch. The mean of the population was allowed to depend on a linear predictor through a non-linear link function $\eta=\ln (p /[1-p])$, allowing the response probability function to follow a binomial probability distribution (Proc Genmod, SAS v8.1). The proportion mature at each temperature was then estimated as $p=$ $\exp (\eta) /[1+\exp (\eta)]$ and converted to proportion mature at the date of first increment formation. The model was run considering the 3 different years separately. The cumulative degree-days from date of first increment formation until the beginning of deposition of the first winter ring, which has been shown to be a good predictor of juvenile size at the end of the first growing season (Reglero \& Mosegaard 2006), was

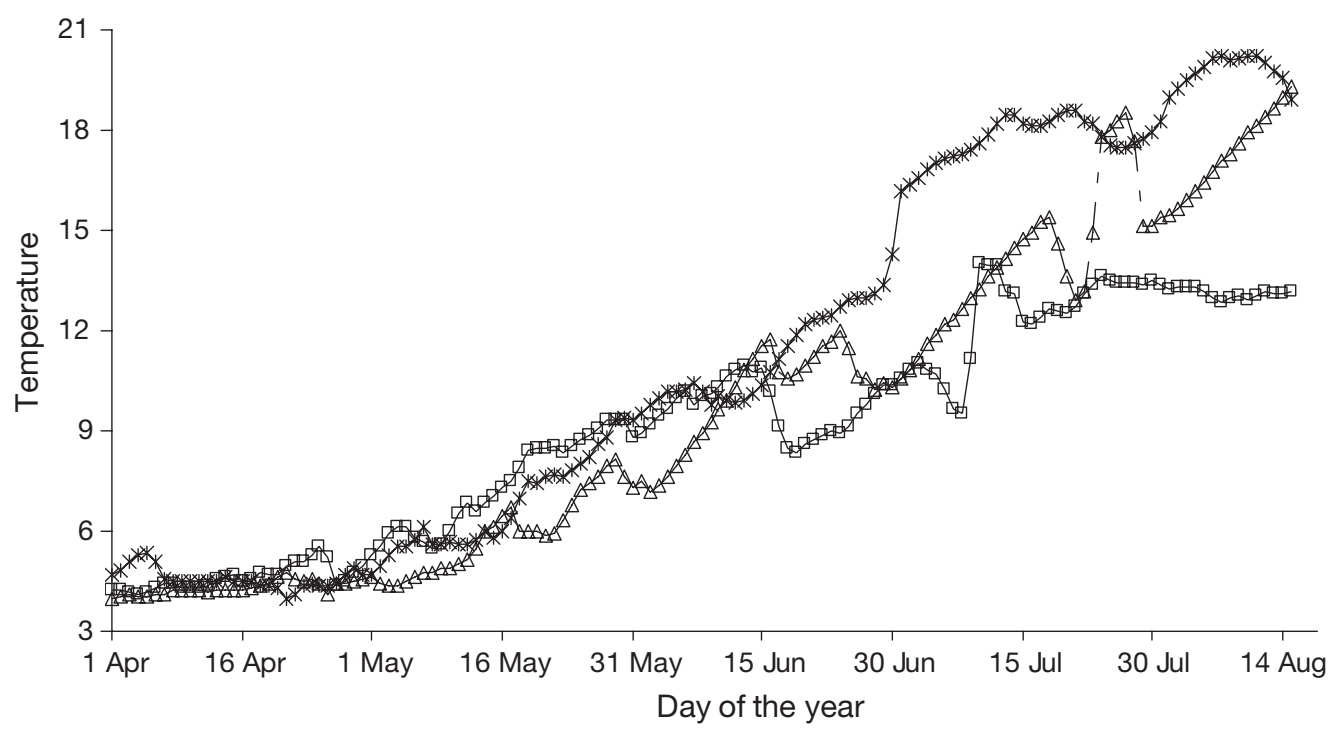

Fig. 2. Average temperature $\left({ }^{\circ} \mathrm{C}\right)$ 0-10 $\mathrm{m}$ depth measured over the sprat-spawning season (1997 to 1999), as estimated from the circulation model: $(\Delta)$ 1997, () 1998 and $(*)$ 1999. Temperatures from 1997 to 1998 were used to estimate date of first microincrement formation in Age 1 sprat 
estimated to identify possible links between date at first increment formation-temperature-juvenile size on the one hand and the probability of maturity occurring at Age 1.

\section{RESULTS}

\section{Temperature regimes}

Temperature conditions during the 3 different years were relatively constant until the middle of May, followed by a gradual increase to about 10 to $12^{\circ}$ in mid-June. After this the temperature rise in each year followed a different pattern: in 1997 values exhibited an uneven path up to $20^{\circ} \mathrm{C}$ by mid-August; in 1998 temperature increased only until mid-July, levelling out at 13 to $14^{\circ} \mathrm{C}$; and in 1999 it increased steadily to a maximum level of 18 to $21^{\circ} \mathrm{C}$ between mid-July and mid-August (Fig. 2). The seasonal temperature curve of the upper layers of the Baltic usuallly has an undulating pattern with an August peak (Fig. 3).

\section{First increment formation}

First increment formation in Sprattus sprattus was closely related to larval length. No discernable increments were visible in otoliths of larvae $<16 \mathrm{~mm}$, whereas otoliths from larger larvae had clear increments out to the edge. The analysis of the otolith radius-larval length relationship revealed that otolith radius (OR) increased steadily with larval size in larvae $>16 \mathrm{~mm}$, associated with the deposition of clear increments (Fig. 4, $\mathrm{R}^{2}=0.9581 ; \mathrm{n}=158 ; \mathrm{OR}[\mu \mathrm{m}]=8.4287 \mathrm{TL}$ [mm] $-105.45 ; \mathrm{p}<0.001)$. Prior to first increment formation, the increase in otolith radius, although increasing with larval length, was much slower $\left(\mathrm{R}^{2}=\right.$

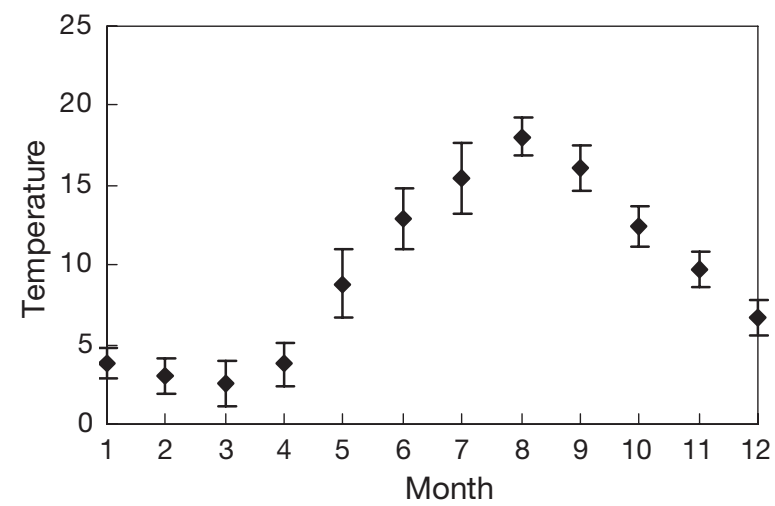

Fig. 3. Average temperature $\left( \pm \mathrm{SE},{ }^{\circ} \mathrm{C}\right) 0-10 \mathrm{~m}$ depth from 1968 to 1994. A general increase in temperatures coincides with the development of the thermocline over the spratspawning season

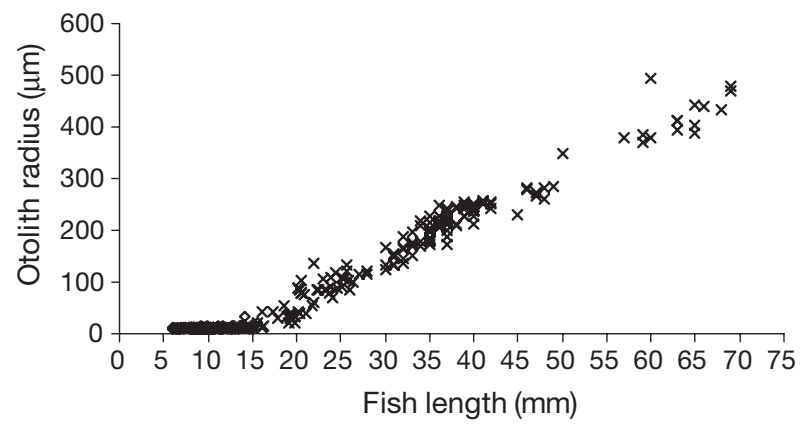

Fig. 4. Sprattus sprattus. Relationship between otolith radius and fish length estimated for sprat in which otoliths did not show clear increments $(\diamond)$ and for sprat in which otoliths showed the first increment followed by subsequent increments $(x)$

0.1615; $\mathrm{n}=193 ; \mathrm{OR}[\mu \mathrm{m}]=0.4224 \mathrm{TL}[\mathrm{mm}]+7.023)$, with an average otolith growth of $0.42 \mu \mathrm{m}$ for $1 \mathrm{~mm}$ growth in larval length. Temperature had no effect on the otolith distance to the first clear increment formation $\left(\mathrm{R}^{2}=0.0012 ; \mathrm{n}=158 ; \mathrm{p}>0.01\right)$.

\section{Temperature influence on otolith growth after first increment formation}

Temperature had a significant effect on the width of the otoliths' first discernable increments (Table 2, p < 0.001). Akaike's information criterion and the loglikelihood ratio test showed that Model 1 fit the data best (Table 2). Therefore, the expression to estimate the influence of temperature on otolith increment width $\left(\frac{\mathrm{d} R}{\mathrm{~d} t}\right)$ was estimated as:

$$
\begin{aligned}
\ln \left(\frac{\mathrm{d} R}{\mathrm{~d} t}\right)= & -0.08697+0.3525 \ln (T)- \\
& 0.5308 \ln (\text { age })+0.3215 \ln (T) \ln (\text { age })
\end{aligned}
$$

where $\ln (T)$ is the $\log$-transformed temperature and the variable 'age' refers to the number of days after first clear increment formation.

\section{Date at first increment formation}

The ln-transformed temperature at first increment formation $\left(\ln \left[T_{1}\right]\right)$ was successfully modelled as a function of otolith increment width by the following expression:

$$
\begin{aligned}
\ln \left(T_{1}\right)= & 0.3465+0.3228 \ln \left(\frac{\mathrm{d} R_{5}}{\mathrm{~d} t}\right)+1.3482 \ln \left(\frac{\mathrm{d} R_{6}}{\mathrm{~d} t}\right)+ \\
& 1.1221 \ln \left(\frac{\mathrm{d} R_{7}}{\mathrm{~d} t}\right)-0.1320 \ln \left(\frac{\mathrm{d} R_{5}}{\mathrm{~d} t}\right) \ln \left(\frac{\mathrm{d} R_{6}}{\mathrm{~d} t}\right) \\
& -0.6366 \ln \left(\frac{\mathrm{d} R_{6}}{\mathrm{~d} t}\right) \ln \left(\frac{\mathrm{d} R_{7}}{\mathrm{~d} t}\right)
\end{aligned}
$$


Table 2. Mixed linear model fit. Model 1 had the lowest Akaike's value and therefore fit the data best. Four different types of covariance structure were implemented in the model to analyse various possible patterns of correlation in the dependent variable of the fitted model. Comparison of the likelihood ratio between Model 1 and each of the other models using the $\chi^{2}$ distribution showed that unstructured covariance fit the data significantly better $(\mathrm{p}<0.001)$

\begin{tabular}{|lccccc|}
\hline $\begin{array}{c}\text { Model Covariance } \\
\text { structure }\end{array}$ & df & $\begin{array}{c}\text { Akaike's } \\
\text { criterion }\end{array}$ & $\begin{array}{c}-2 \text { Log } \\
\text { likelihood }\end{array}$ & Comparison \\
Model 1
\end{tabular}

where $\mathrm{d} R_{\mathrm{day}} / \mathrm{d} t$ is the otolith increment width at a given age in days. The model explained $63 \%$ of the variance. Only the increment widths observed on Days 5 to 7 , and the interaction between Days 5 and 6 and Days 6 and 7 had a significant effect $(p<0.001)$ on the temperature at first increment formation. Temperatures inferred from otoliths with higher growth rates were warmer than the ones showing lower growth rates (Fig. 5).

Using the first, second and third increments identified at $30 \mu \mathrm{m}$ from the core

$$
\left(\frac{\mathrm{d} R_{1}}{\mathrm{~d} t}, \frac{\mathrm{d} R_{2}}{\mathrm{~d} t}, \frac{\mathrm{d} R_{3}}{\mathrm{~d} t}\right)
$$

instead of $\frac{\mathrm{d} R_{5}}{\mathrm{~d} t}, \frac{\mathrm{d} R_{6}}{\mathrm{~d} t}, \frac{\mathrm{d} R_{7}}{\mathrm{~d} t}$

in Eq. (2) yielded in $85 \%$ of the cases differences in estimated temperatures of $<1^{\circ} \mathrm{C}$, with a maximum in temperature differences of $3^{\circ} \mathrm{C}$.

Estimated temperatures at first increment formation using Eq. (2) were very similar to the ones from the circulation model for larvae caught in 1999 (Fig. 6). Transformed to date of first increment formation, differences between observed and estimated dates were normally distributed (Shapiro-Wilk, p = 0.2301), with an average difference in date of first increment formation of $5.8 \mathrm{~d}$. The SD was 9.5; therefore, the $95 \%$ confidence limits for the mean were calculated as $5.8 \pm$ $1.96 \times 9.5$, giving a lower limit of -3.8 and an upper limit $15.2 \mathrm{~d}$.
Temperatures at first increment formation were calculated for Age 1 survivors caught from 1998 to 2000 (Year Classes 1997, 1998 and 1999, respectively) using Eq. (2). Trends in the estimated temperatures were almost identical for the 1997 and 1999 year classes, with $<20 \%$ of individuals forming the first increment at temperatures $<16^{\circ} \mathrm{C}$, whereas, for the 1998 year class, most individuals formed it at colder temperatures (Fig. 7). This pattern is in accordance with the distinct temperature regime in 1998, when temperatures were colder than those in 1997 and 1999 (Fig. 2).

Back-calculated dates of first increment formation differed between the 1997 and 1999 year classes (Fig. 8). In the 1997 year class most survivors formed it from late July to the beginning of August, whereas in the 1999 year class most individuals formed the first increment in early July. For the 1998 year class, most fish formed their first clear increment before July, but the distribution was much more extended in time. Still, individuals of this year class forming their first increment from early July to mid-August were difficult to distinguish by looking at the correspondence between estimated temperature and day of the year, given the similar temperatures over time late in the season (Fig. 2).
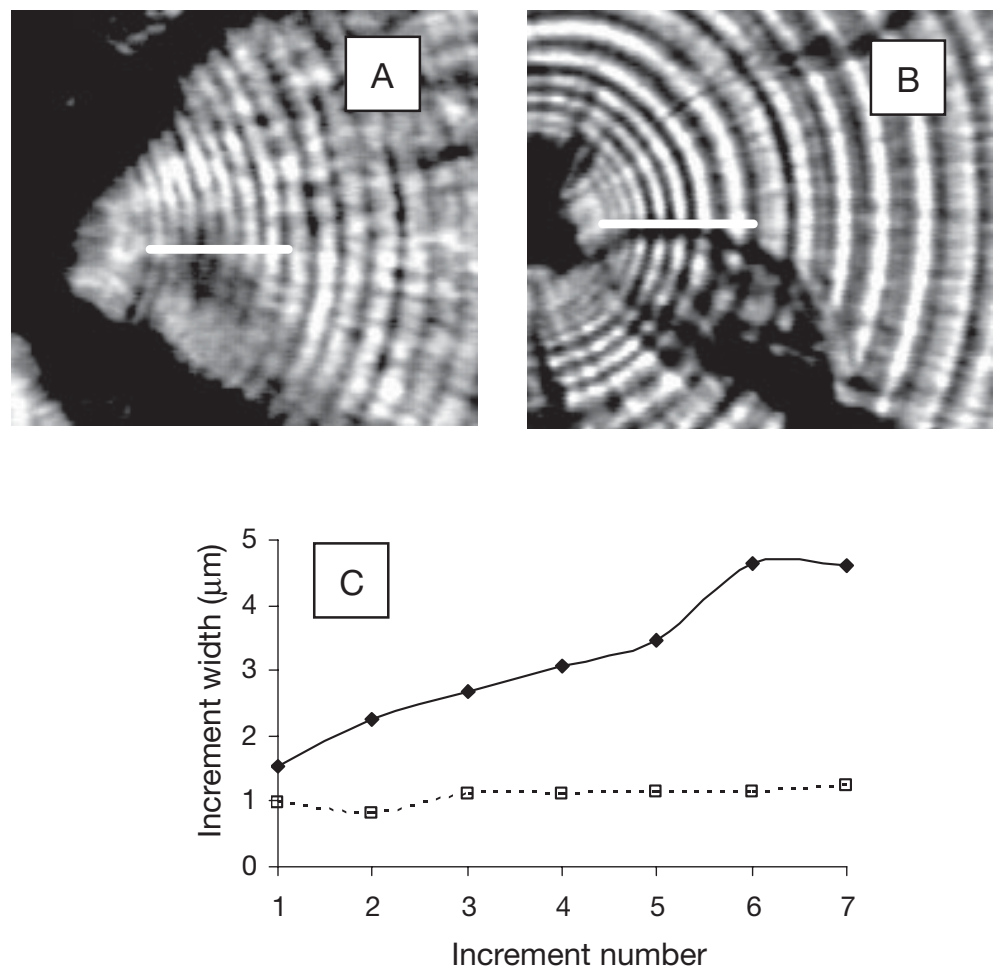

Fig. 5. Sprattus sprattus. Otolith microstructure of 2 otoliths forming first increment formation at (A) $10^{\circ} \mathrm{C}$ and (B) $18^{\circ} \mathrm{C}$, respectively. White line: increment width measurements for the 7 first increments. (C) Increment values (in $\mu \mathrm{m})$ for each otolith $\left(\bullet: 18^{\circ} \mathrm{C}\right.$ otolith; $\square: 10^{\circ} \mathrm{C}$ otolith) 


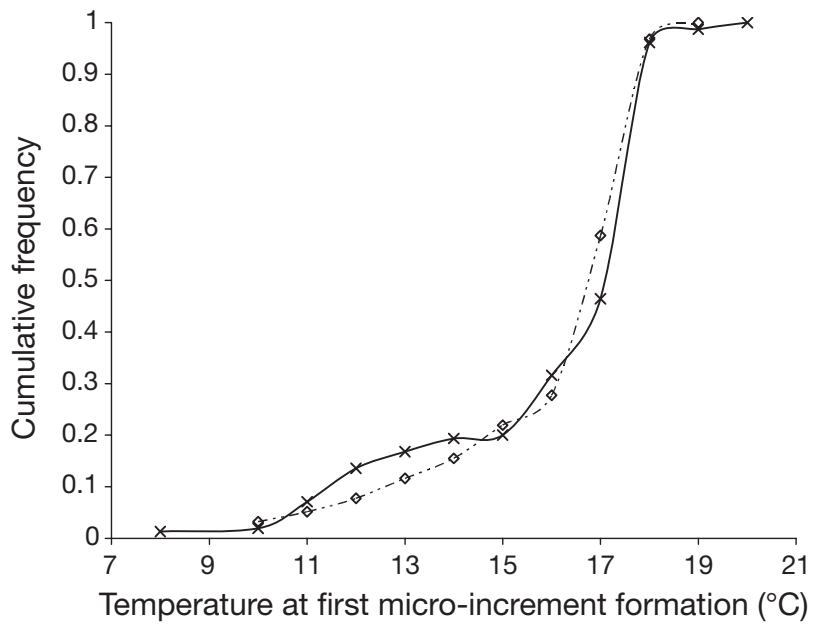

Fig. 6. Sprattus sprattus. Comparison of temperature at first increment formation in larvae caught during 1999, estimated from Eq. (2) (broken line) and from the circulation model (continuous line)

\section{Differences in the onset of maturity among Age 1 individuals}

The results from the models showed a significant effect of date of first increment formation on the proportion mature at Age 1, when temperature at first increment formation was used as a proxy for date. For the 1997 and 1999 year classes, we observed that a higher proportion of sprat that form the first increment at colder temperatures mature as Age 1 as compared to those forming it at warmer temperatures (Proc GENMOD, SAS v8.1) ( $p=0.0009$ and $p=0.0420$ for the 1997 and the 1999 year classes, respectively). The absolute proportions, however, differed between the two years (Fig. 9). Converted to date, we found that sprat forming their first increment earlier in the season matured at

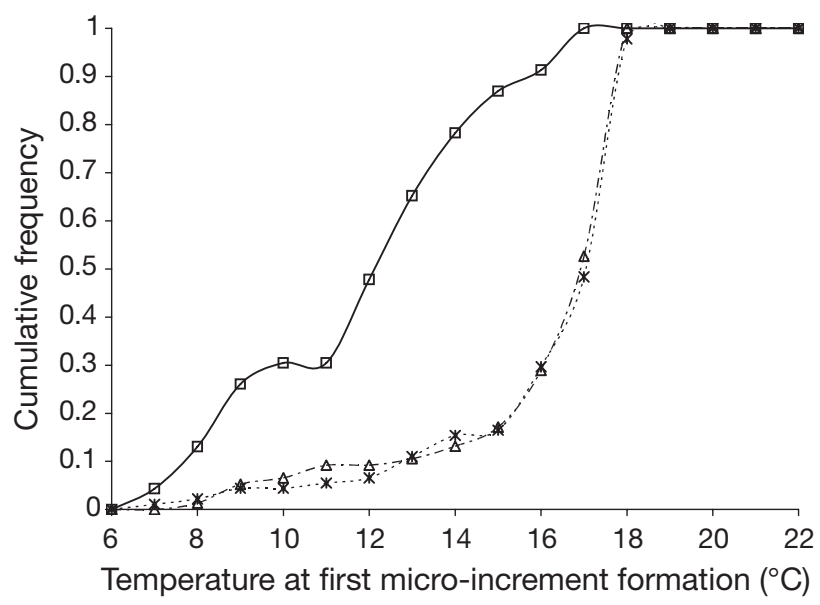

Fig. 7. Sprattus sprattus. Temperature at first increment formation estimated for Age 1 sprat from the $1997(\Delta), 1998(\square)$ and $1999(*)$ year classes

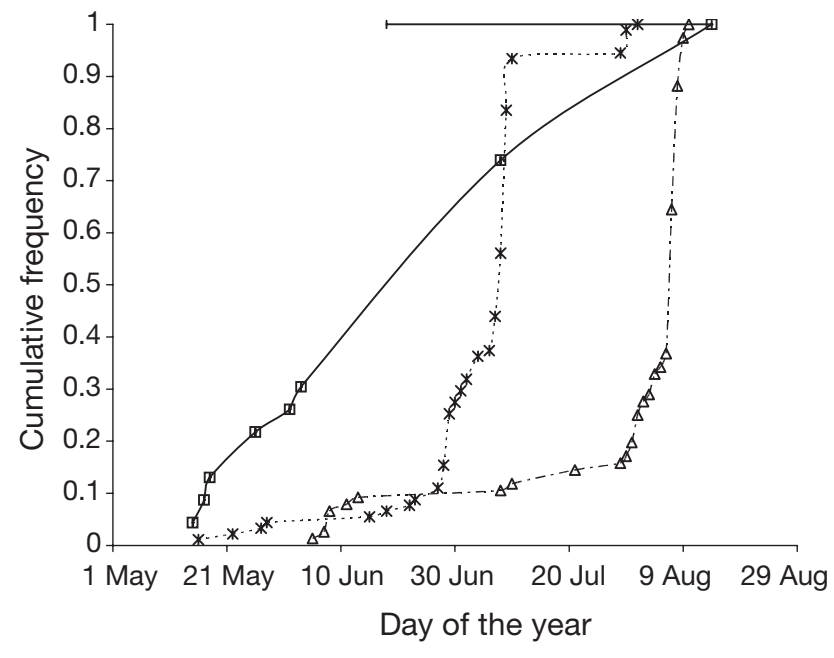

Fig. 8. Sprattus sprattus. Date at first increment formation for Age 1 sprat from the $1997(\Delta), 1998$ () and $1999(*)$ year classes. Horizontal error bar shown for 1998 year class illustrates the difficulty in estimating the day of first increment formation when temperatures are very similar over time

Age 1 in higher proportion than the ones forming it later (Fig. 10). No such trend was found for the 1998 year class (Proc GENMOD, SAS v8) (Fig. 9, p = 0.8985). The overall result is that larvae reaching the size of $16 \mathrm{~mm}$ early in the season in one of the warm years (1997 and 1999) are more likely to mature the following year, whereas larvae reaching this stage late in the season in a warm year are less likely to mature the following year. In cold years the probability of maturating the following year is similarly independent of the time when the larvae achieved the size of $16 \mathrm{~mm}$. The cumulated degree-days from the date when larvae

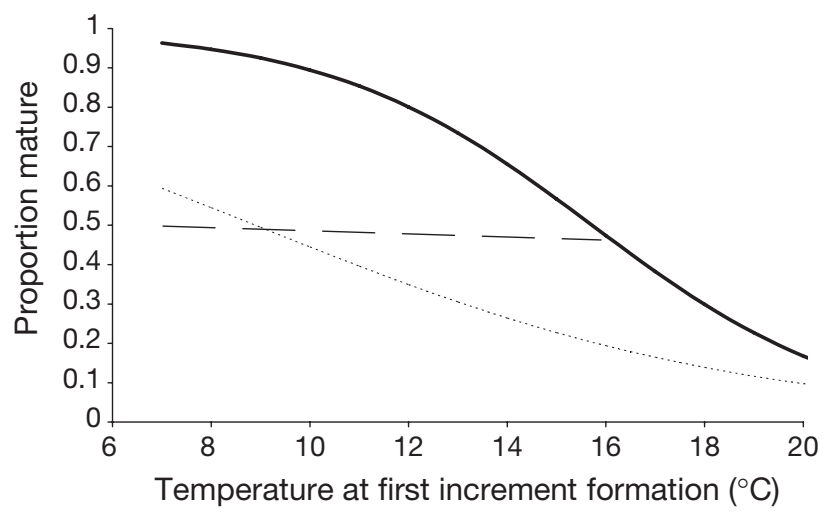

Fig. 9. Sprattus sprattus. Proportion mature at Age 1 calculated for the year classes 1997 (continuous line), 1998 (dashed line) and 1999 (dotted line), as a function of temperature at first increment formation. The relationship is significant for the 1997 and 1999 year classes $(p=0.0009$ and $p=0.0420$, respectively) and not significant for the 1998 year class $(\mathrm{p}=$ 0.8985). Only data up to the maximum temperature of $16^{\circ} \mathrm{C}$ achieved in 1997 are shown for the 1998 year class 


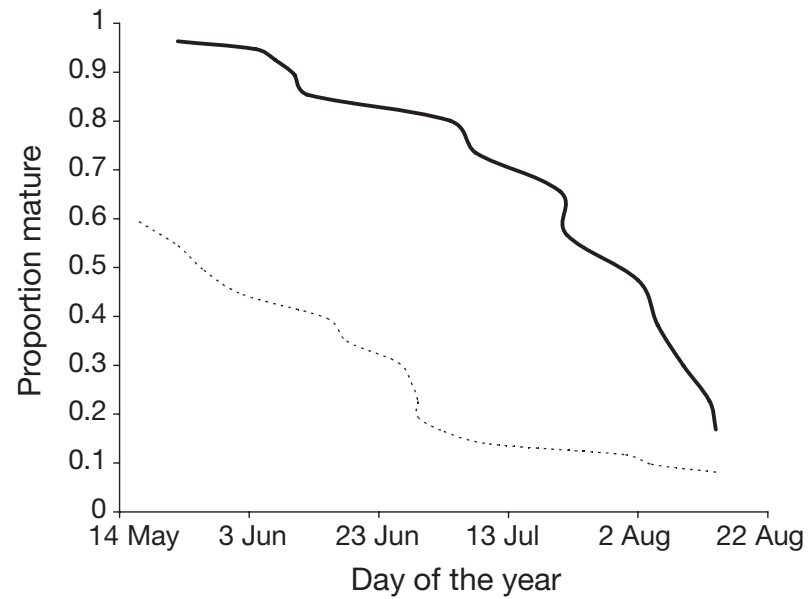

Fig. 10. Sprattus sprattus. Proportion mature at Age 1 calculated for the year class 1997 (continuous line) and 1999 (dotted line), as a function of date of first increment formation

were $16 \mathrm{~mm}$ to the beginning of the formation of the first winter ring were higher for larvae that were 16 mm long earlier in the season for all 3 years (1997 to 1999) (Fig. 11). However, larvae forming their first increment at similar dates during 1997 and 1999 had similar cumulated degree-days until the formation of the first winter ring, whereas, for the 1998 year class, the cumulated degree-days were lower.

\section{DISCUSSION}

Using the date of first increment formation as a proxy for life-history traits is a widespread practice in fish ecology. Although the life-history event that is most connected to the first clear increment formation varies among species and environments, one common feature is that after the first clear increment is formed reg-

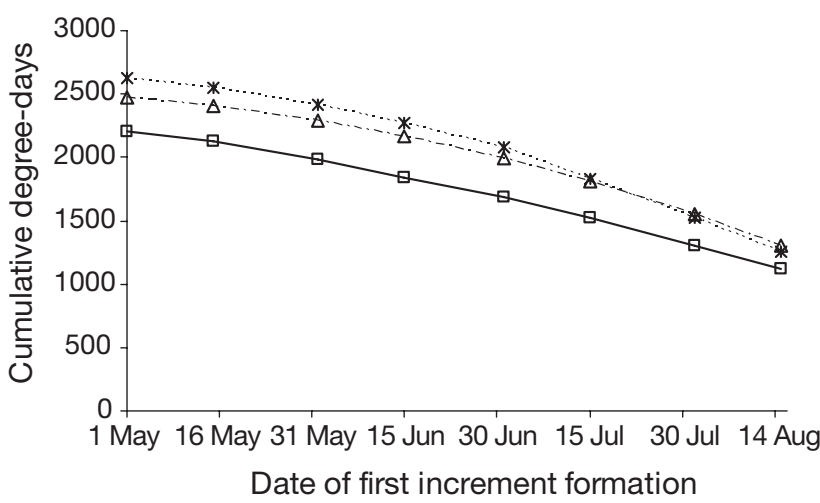

Fig. 11. Sprattus sprattus. Cumulated degree-days from the date when larvae reached $16 \mathrm{~mm}$ until the beginning of formation of the first winter ring (assumed to occur on 15 November) for the years classes $1997(\Delta), 1998$ (ㅁ) and $1999(*)$ ular increments are deposited at larval growth rates above $0.4 \mathrm{~mm} \mathrm{~d}^{-1}$ (Geffen 1982, Folkvord et al. 2000, Fox et al. 2003). In our study, the first increment formation and subsequent regular deposition were closely related to larval length, a result that can be interpreted within the context of length-based growth rates.

Somatic growth rates $<0.2 \mathrm{~mm} \mathrm{~d}^{-1}$ are expected at the cold temperatures of 4 to $5^{\circ} \mathrm{C}$ that characterise the stable intermediate layers where Baltic sprat Sprattus sprattus eggs and early larvae develop (Nissling 2004). These low somatic growth rates would induce the low otolith growth rates found for small larvae, which are in the range of those reported for other clupeids (Folkvord et al. 2004). In this approach, the increase of somatic growth rates (to levels $>0.4 \mathrm{~mm} \mathrm{~d}^{-1}$ ) with increasing sprat size would explain the deposition of the first clear increment and subsequent regular increments at lengths $>16 \mathrm{~mm}$. Somatic growth also varies with temperature (Otterlei et al. 1999), and, in otoliths, it is expected that there will be shorter distances to the first increment formation followed by wider increments at higher temperatures (Høie et al. 1999, Otterlei et al. 2000). In our study, distance to the first clear increment formation was independent of temperature. Only after the first increment formation did subsequent regular increments increase with temperature at rates similar to those found in other species (Neilson \& Geen 1982, Mosegaard \& Titus 1987, Hoff \& Fuiman 1993, Folkvord et al. 2004). These results are in accordance with a predominance of $16 \mathrm{~mm}$ long larvae found above the thermocline, whereas smaller larvae develop in stable cold water layers (Wieland \& Zuzarte 1991, Makarchouk \& Hinrichsen 1998). Growth rates may also be influenced by the feeding conditions experienced by the larvae. Sprat individuals caught in mixed areas have been found to grow faster compared to those experiencing poorer feeding conditions in stratified waters (Munk 1993).

Comparisons with other studies reveal that a wide range of dates for the first clear increment deposition have been reported for sprat. In the laboratory, the deposition of well-defined increments occurred at $5 \mathrm{~mm}$ at a temperature of $15^{\circ} \mathrm{C}$, although no increments were formed at colder temperatures (Alshut 1988). In field studies, reported data differ among environments. For North Sea sprat, clear increments were visible only in larvae $>11 \mathrm{~mm}$ at 10 to $13^{\circ} \mathrm{C}$ (Ré \& Gonçalves 1993) and 10 to $16^{\circ} \mathrm{C}$ (Munk 1993). In the northern Adriatic, increments were already found at lengths of $7 \mathrm{~mm}$ at $10^{\circ} \mathrm{C}$ (Dulčić 1998). Despite differences, the studies that showed otolith increment formation reported average growth rates of around $0.4 \mathrm{~mm} \mathrm{~d}^{-1}$. However, the change in the otolith size-larval length relationship with larval length found in our study agrees with previous results (Dulčić 1998). The problems of finding 
general guidelines for the first clear increment formation in sprat may be avoided if increment deposition is analysed in relation to length, somatic growth rate and temperature.

The apparent absence of daily increments before the first increment formation has been related to the resolution limitations of standard optimal microscopy rather than to a real lack of increment formation (Campana et al. 1987). However, further studies of herring otoliths by SEM identified the presence of irregular crystal structures, but did not provide evidence that increments were present and not identified (Fox et al. 2003). Therefore, no significant improvement in locating the first clear increment in Baltic sprat otoliths is expected even using SEM.

The most general application to date is using the date of first increment formation as a proxy for hatch date (Moksness 1992, Moksness \& Fossum 1992, Arrhenius \& Hansson 1996). Our data show that the date of first increment formation is a good predictor of larval size (date that larvae were $16 \mathrm{~mm}$ in length). Given that sprat length at hatch is $3 \mathrm{~mm}$, we did not adopt the common practice, based on the experiment by Alshuth (1988), of adding a fixed number of $7 \mathrm{~d}$ to the day of first increment formation to account for the period prior to the onset of regular deposition. However, if, as suggested in this study, sprat growth rates are only size dependent prior to the first increment formation, then another fixed number could be derived by estimating the number of days necessary to grow to $16 \mathrm{~mm}$. Nevertheless, we suggest that size- and temperature-dependent growth models are developed further and applied to several environments before the date of first increment formation can be directly related to hatch date. These types of models have already been suggested to be an optimal tool for comparing larval growth performance in different scenarios (Folkvord 2005).

\section{Date of first increment formation and maturity of adult sprat}

One main problem in linking the characteristics of the larvae tied to date of first increment formation with other traits later in life is the difficulty of determining date of first increment formation in adults. This issue has been avoided in other studies where the survivor fraction analysed had not formed their first winter ring yet (Wright \& Bailey 1996, Narimatsu \& Munehara 1999). However, because sprat do not mature before Age 1, it was necessary - after the formation of the first winter ring - to develop a method to estimate the date of first daily increment formation from adult sprat otoliths, avoiding the problem of winter ring formation breaking the continuous sequence of daily increments.

Our method appears to be quite reliable when backcalculating temperature at first increment formation. Still, some otolith growth trajectories may be slightly underrepresented if selective mortality occurs, given that sprat larvae with well-defined increments were first caught in July even if their first increment was formed at colder temperatures. The available time series of daily temperatures in this study provided a detailed description of short-term changes in temperature over time, so that back-calculated dates had a high temporal resolution compared to the seasonal resolution in other studies (Moksness 1992, Fossum \& Moksness 1993, Zhang \& Moksness 1993, Mosegaard \& Madsen 1996, Stenevik et al. 1996, Fey 2001). The method may lose resolution in exceptional years when temperatures are homogeneous over time, such as in 1998, or early in the season, with stable temperatures over an extended period of time.

We related the date of first increment formation to the onset of maturity and found that a higher proportion of sprat that formed the first increment early in the season matured at Age 1 compared to those that formed it later, although absolute proportions differed between years. Age at first maturity has been linked to the size attained during the first growing season, with larger sprat maturating at Age 1 and smaller sprat maturing at Age 2 (Reglero \& Mosegaard 2006). Within this context, sprat larvae that were $16 \mathrm{~mm}$ long earlier in the season may reach a larger size during the first growing season and mature at Age 1. In comparison, larvae that were $16 \mathrm{~mm}$ long later in the season may reach a smaller juvenile size at the end of the first growing season and mature at Age 2. These patterns are very marked in year classes from warm years, such as the 1997 and 1999 year classes. The higher cumulated degree-days until the formation of the first winter ring for larvae that were $16 \mathrm{~mm}$ long earlier in the season could explain the higher proportion mature at Age 1 compared to those that were $16 \mathrm{~mm}$ long later in the season in the 1997 and 1999 year classes. Temperature coupling during juvenile growth would, on the other hand, explain differences in otolith size at the formation of the first winter ring, which has been linked to the size attained during the first growing season and therefore further maturity (Reglero \& Mosegaard 2006), among sprat born during the same spawning season.

In year classes like 1998 from cold years, the proportion mature at Age 1 was found to be independent of the date at which larvae were $16 \mathrm{~mm}$ long, suggesting that some other processes may need to be considered when the relationship between hatching date and onset of maturity is analysed. Recruitment estimates derived from multispecies virtual population analysis showed 
the abundance of Age 1 sprat from the 1998 year class was less abundant, compared to the 1997 and the 1999 year classes, in which abundances were 7 to 9 times higher, with a value close to the lowest ever found for Baltic sprat (ICES 2003). Low population abundances may be more likely with density-independent settings, leading to earlier maturation through enhanced growth by, for example, diminishing competition for food resources, as postulated for anchovy populations (Rose et al. 1999). In other clupeids, changes in the length and age at maturity have been related to a decrease in the population abundance experienced during juvenile growth (Winters 1976, Hubold 1978, Sinclair et al. 1982). It has been found that sprat that are fast growing as juveniles generally participate in the first part of the spawning season, whereas more slowly growing juveniles dominate as spawners in the later part of the first - as well as in the second - spawning season as Age 1 and Age 2 adults (Reglero \& Mosegaard 2006). If spawning, hatch and early development are linked in time, there may be a basis for 2 coexisting growth traits, with corresponding generation cycles in Baltic sprat: one early season spawning with fast growth and a 1 yr generation cycle and another later spawning with slower growth and a predominantly 2 yr generation cycle. The balance between the 2 may be determined by growth and temperature conditions for survival of early spawned individuals, and by general summer temperatures and larval/juvenile feeding conditions for both growth traits/generation cycles.

Compared to its extended use in fisheries management studies, the use of otolith information to develop theories of life history has to date received little attention for most species (McFarlane \& Geffen 2000). Particularly for sprat, studies in which otolith-derived information has been used are relatively scarce. In our study, otolith microstructure analysis was used to estimate date of first increment formation from samples of later life stages of sprat: juveniles and adults. Hence, differences in the date of first increment formation among larvae born at different times during the same spawning season could be identified through later parts of their life, and important links between early development and the maturation cycle could be established. Although in the present study we have focused on the relationship between larval traits and the onset of maturity of Age 1 sprat, the study points to important life-history trade-offs between spawning season, larval traits, juvenile growth and later maturation and spawning periods that may be investigated quantitatively on an individual level. Thus, we see the approach as an improvement for further studies relating time of first increment formation to lifetime fitness of fish species, a task that has received relatively little attention in the literature (Schultz 1993, Wright \& Gibbs 2005).
Acknowledgements. We thank Stina Bilstrup, Troels Forum Askgaard and the staff in the laboratory and on the research cruises for helping with fish collection and analysis. Thanks also to Margit Eero who collaborated in the analysis of the larvae and otolith samples. Peter Levy helped with the statistical treatment of the data. Part of this study was carried out during P.R.'s time at the Instituto Mediterráneo de Estudios Avanzados (Spain), and thanks are due to Dr. Beatriz Morales-Nin for the support she provided. This study was partly funded by a TMR Marie Curie Research Training Grant (Project No. ERB4001GT9-2010) to P.R. and by the Baltic STORE project (FAIR CT 98 3959).

\section{LITERATURE CITED}

Alekseejev FE, Alekseejeva EI (1996) Assessment of gonad maturity stages and study of sex cycles, fecundity, egg production and maturation rate of marine commercial fishes. Methodological manual. Atlantniro, Kaliningrad

Alheit J (1988) Reproductive biology of sprat (Sprattus sprattus): factors determining annual egg production. J Cons Int Explor Mer 44:162-168

Alshuth S (1988) Daily growth increments on otoliths of laboratory-reared sprat, Sprattus sprattus L., larvae. Meeresforschung 32:23-29

Arrhenius F, Hansson S (1996) Growth and seasonal changes in energy content of young Baltic Sea herring (Clupea harengus L.). ICES J Mar Sci 53:792-801

Campana SE, Jones CM (1992) Analysis of otolith microstructure data. In: Stevenson DK, Campana SE (eds) Otolith microstructure examination and analysis. Can Spec Publ Fish Aquat Sci 117:73-100

Campana SE, Neilson JD (1985) Microstructure of fish otoliths. Can J Fish Aquat Sci 42:1014-1032

Campana SE, Gagné JA, Munro J (1987) Otolith microstructure of larval herring (Clupea harengus): image or reality? Can J Fish Aquat Sci 44:1922-1929

Dulčić J (1998) Larval growth of sprat, Sprattus sprattus phalericus, larvae in the northern Adriatic. Fish Res 36: $117-126$

Fey DP (2001) Differences in temperature conditions and somatic growth rate of larval and early juvenile springspawned herring from the Vistula Lagoon, Baltic Sea manifested in the otolith to fish size relationship. J Fish Biol 58:1257-1273

Folkvord A (2005) Comparison of size-at-age of larval Atlantic cod (Gadus morhua) from different populations based on size- and temperature-dependent growth models. Can J Fish Aquat Sci 62: 1037-1052

Folkvord A, Blom G, Johannessen A, Moksness E (2000) Growth-dependent age estimation in herring (Clupea harengus L.) larvae. Fish Res 46:91-103

Folkvord A, Johannessen A, Moksness E (2004) Temperature-dependent otolith growth in Norwegian springspawning herring (Clupea harengus L.) larvae. Sarsia 89:297-310

Fossum P, Moksness E (1993) A study of spring- and autumnspawned herring (Clupea harengus L.) larvae in the Norwegian Coastal Current during spring 1990. Fish Oceanogr 2:73-81

Fox CJ, Fokvord A, Geffen AJ (2003) Otolith micro-increment formation in herring Clupea harengus larvae in relation to growth rate. Mar Ecol Prog Ser 264:83-94

Geffen AJ (1982) Otolith ring deposition in relation to growth rate in herring (Clupea harengus) and turbot (Scophthalmus maximus) larvae. Mar Biol 71:317-326 
Hoff GR, Fuiman LA (1993) Morphometry and composition of red drum otoliths: changes associated with temperature, somatic growth rate, and age. Comp Biochem Physiol A 106(2):209-219

Høie H, Folkvord A, Johannessen A (1999) Maternal, paternal and temperature effects on otolith size of young herring (Clupea harengus L.) larvae. J Exp Mar Biol Ecol 234:167-184

Hubold G (1978) Variations in growth rate and maturity of herring in the northern North Sea in the years 1955-1973. Rapp P-V Reun Cons Int Explor Mer 172:154-163

ICES (International Council for the Exploration of the Sea) (2003) Report of the study group on multispecies assessment in the Baltic. ICES Comm Meet 2003/H:03. International Council for the Exploraion of the Sea, Copenhagen

Killworth PD, Stainforth D, Webbs DJ, Paterson SM (1991) The development of a free-surface Bryan-Cox-Semtner ocean model. J Phys Oceanogr 21:1333-1348

Lehmann A (1995) A three-dimensional baroclinic eddyresolving model of the Baltic Sea. Tellus 47A:1013-1031

Makarchouk A, Hinrichsen HH (1998) The vertical distribution of ichthyoplankton in relation to the hydrographic conditions in the eastern Baltic. ICES Comm Meet 1998/R: 11. International Council for the Exploraion of the Sea, Copenhagen

Marshall SL, Parker SS (1982) Pattern identification in the microstructure of sockeye salmon (Oncorhynchus nerka) otoliths. Can J Fish Aquat Sci 39:542-547

McFarlane GA, Geffen A (2000) Section 3: otoliths in studies of populations. Fish Res 46:189-190

Moksness E (1992) Differences in otolith microstructure and body growth rate of North Sea herring (Clupea harengus L.) larvae in the period 1987-1989. ICES J Mar Sci 49

Moksness E, Fossum P (1992) Daily growth rate and hatchingdate distribution of Norwegian spring-spawning herring (Clupea harengus L.). ICES J Mar Sci 49:217-221

Møller JS, Hansen IS (1994) Hydrographic processes and changes in the Baltic Sea. Dana 10:87-104

Mosegaard H, Madsen KP (1996) Discrimination of mixed herring stocks in the North Sea using vertebral counts and otolith microstructure. ICES Comm Meet 1996/H:17

Mosegaard H, Titus RG (1987) Daily growth rates of otoliths in yolk sac fry of two salmonid species at five different temperatures. Proc V Congr Europ Ichthyol, Stockholm 1985: 221-227

Mosegaard H, Svedang H, Taberman K (1988) Uncoupling of somatic and otolith growth-rates in arctic char (Salvelinus alpinus) as an efffect of differences in temperature response. Can J Fish Aquat Sci 45:1514-1524

Munk P (1993) Differential growth of larval sprat Sprattus sprattus across a tidal front in the eastern North Sea. Mar Ecol Prog Ser 99:17-27

Narimatsu Y, Munehara H (1999) Spawn date dependent survival and growth in the early life stages of Hypoptychus dybowskii (Gasterosteiformes). Can J Fish Aquat Sci 56: 1849-1855

Neilson JD, Geen GH (1982) Otoliths of chinook salmon (Oncorhynchus tshawytscha): daily growth increments and factors influencing their production. Can J Fish Aquat Sci 39:1340-1347

Editorial responsibility: Otto Kinne (Editor-in-Chief), Oldendorf/Luhe, Germany
Nissling A (2004) Effects of temperature on egg and larval survival of cod (Gadus morhua) and sprat (Sprattus sprattus) in the Baltic Sea-implications for stock development. Hydrobiologia 514: 115-123

Otterlei E, Nyhammer G, Folkvord A, Stefansson SO (1999) Temperature- and size-dependent growth of larval and juvenile cod (Gadus morhua): a comparative study between Norwegian coastal cod and northeast Arctic cod. Can J Fish Aquat Sci 56: 2099-2111

Otterlei E, Folkvord A, Nyhammer G (2000) Temperature dependent otolith growth of larval and early juvenile Atlantic cod (Gadus morhua). Temperature- and sizedependent growth of larval and early juvenile Atlantic cod (Gadus morhua L.). Department of Fisheries and Marine Biology, University of Bergen

Ré P, Gonçalves E (1993) Growth of sprat Sprattus sprattus larvae in the German Bight (North Sea) as inferred by otolith microstructure. Mar Ecol Prog Ser 96:139-145

Reglero P (2004) The life history strategy of sprat (Sprattus sprattus) in the Baltic ecosystem. PhD thesis, Faculty of Marine Science, University of Cádiz

Reglero P, Mosegaard H (2006) Onset of maturity and cohort composition at spawning of Baltic sprat Sprattus sprattus on the basis of otolith macrostructure analysis. J Fish Biol 68:1091-1106

Rose KA, Cowan JH, Clark ME, Houde ED, Wang SB (1999) An individual-based model of bay anchovy population dynamics in the mesohaline region of Chesapeake Bay. Mar Ecol Prog Ser 185:113-132

Schultz ET (1993) The effect of birth date on fitness of female dwarf perch, Micrometrus minimus (Perciformes: Embiotocidae). Evolution 47:520-539

Sinclair M, Sinclair A, Iles TD (1982) Growth and maturation of southwest Nova Scotia Atlantic herring (Clupea harengus harengus). Can J Fish Aquat Sci 39: 288-295

Stenevik EK, Fossum P, Johannessen A, Folkvord A (1996) Identification of Norwegian spring spawning herring (Clupea harengus L.) larvae from spawning grounds off western Norway applying otolith microstructure analysis. Sarsia 80:285-292

Wieland K, Zuzarte F (1991) Vertical distribution of cod and sprat eggs and larvae in the Bornholm Basin (Baltic Sea) 1987-1990. ICES Comm Meet 1991/J:37. International Council for the Exploraion of the Sea, Copenhagen

Winters GH (1976) Recruitment mechanisms of southern Gulf of St. Lawrence Atlantic herring (Clupea harengus harengus). J Fish Res Board Can 33:1751-1763

Wright PJ, Bailey MC (1996) Timing of hatching in Ammodytes marinus from Shetland waters and its significance to early growth and survivorship. Mar Biol 126:143-152

Wright PJ, Gibbs FM (2005) Selection for birth date in North Sea haddock and its relation to maternal age. J Anim Ecol 74:303-312

Zhang Z, Moksness E (1993) A chemical way of thinning otoliths of adult Atlantic herring (Clupea harengus) to expose the microstructure in the nucleus region. ICES J Mar Sci 50:213-217

Submitted: December 23, 2002; Accepted: May 23, 2006 Proofs received from author(s): December 20, 2006 